\title{
Produtividade de soja em consequência do atraso da colheita e de condições ambientais
}

\author{
Rodrigo Yoiti Tsukahara(1), Inês Cristina de Batista Fonseca( ${ }^{(2)}$, Marcelo Augusto de Aguiar e Silva(2), \\ Edson Giovanni Kochinski(1), José Prestes Neto(1) e Juliana Tamie Suyama ${ }^{(1)}$
}

\begin{abstract}
(1)Fundação ABC, Pesquisa e Desenvolvimento Agropecuário, Setor de Agrometeorologia, Rodovia PR-151, Km 288, Caixa Postal 1003, CEP 84165-970 Castro, PR, Brasil. E-mail: rodrigo@fundacaoabc.org.br, giovanni@fundacaoabc.org.br, jose.neto@fundacaoabc.org.br, juliana.tamie@fundacaoabc.org.br (2)Universidade Estadual de Londrina, Departamento de Agronomia, Campus Universitário, Caixa Postal 6001, CEP 86051-990 Londrina, PR, Brasil. E-mail: inescbf@uel.br, aguiaresilva@uel.br
\end{abstract}

Resumo - O objetivo deste trabalho foi avaliar o efeito do atraso da colheita sobre umidade dos grãos, massa de mil grãos e produtividade da soja, assim como identificar as variáveis agrometeorológicas mais importantes durante o período pré-colheita e propor algoritmos empíricos para a estimativa das perdas de produtividade. Os experimentos foram realizados em Castro, PR, e Itaberá, SP, nas safras de 2011/2012 a 2013/2014, da cultivar de soja 'NA5909RG', em sete ambientes. Os tratamentos consistiram de oito momentos de colheita de soja a partir do estádio fenológico R8.2. A análise de grupos de experimentos mostrou interação significativa entre ambientes e momentos de colheita. A umidade e a produção de grãos são influenciadas diretamente pelo número de dias com precipitação pluvial igual ou superior a $3 \mathrm{~mm}$. No estádio fenológico R8.2, são obtidos os maiores valores de produtividade; no entanto, após esse estádio, há declínio da produtividade em consequência do atraso da colheita. As maiores perdas acumuladas de produtividade ocorrem em ambientes com alta frequência de precipitações pluviais e com temperatura e radiação solar global elevadas. Dois algoritmos com base em variáveis agrometeorológicas são propostos para a estimativa da perda de produtividade de soja.

Termos para indexação: Glycine max, pré-colheita, precipitação pluvial, radiação solar.

\section{Soybean yield as a consequence of harvest delay and environmental conditions}

\begin{abstract}
The objective of this work was to evaluate the effect of harvest delay on grain moisture, thousand grain weight, and soybean productivity, as well as to identify the most important meteorological variables during pre-harvest and to propose empirical algorithms to estimate soybean yield losses. The experiments were carried out in the municipalities of Castro, in the state of Paraná, and of Itaberá, in the state of São Paulo, Brazil, in the seasons from 2011/2012 to 2013/2014, with the soybean cultivar 'NA5909RG', in seven environments. Treatments consisted of eight harvest times of soybean after phenological stage R8.2. The analysis of group of experiments showed a significant interaction between environments and harvest times. Grain moisture and grain yield are directly affected by the number of days with rainfall equal to or higher than $3 \mathrm{~mm}$. At the R8.2 phenological stage, the highest values of productivity are obtained; however, after this stage, there is a decline of productivity as a consequence of harvest delay. The greatest, accumulated losses of productivity occur in environments with high frequency of rainfall, and high temperature and solar radiation. Two algorithms based on agrometeorological variables are proposed to estimate soybean yield loss.
\end{abstract}

Index terms: Glycine max, pre-harvest, rainfall, solar radiation.

\section{Introdução}

O período pré-colheita, que se inicia na maturação fisiológica dos grãos e se estende até a operação de colheita, pode ser considerado como uma das etapas mais críticas dentro do processo de produção, em razão da suscetibilidade dos aspectos quantitativos, qualitativos e sanitários das sementes às intempéries meteorológicas como a precipitação pluvial, umidade relativa e temperatura do ar (Daltro et al., 2010).
A maturação fisiológica pode ser identificada visualmente, a partir do predomínio da cor marrom ou palha das vagens, em qualquer nó da haste principal, acompanhado do amarelecimento das folhas (Câmara, 2006). Fisiologicamente, este momento representa o ponto máximo de acúmulo de matéria seca e teores de água em torno de $55 \%$, fato este que inviabiliza a colheita mecanizada, em razão da quantidade excessiva de partes verdes e úmidas das plantas e da possibilidade de se causar injúrias 
mecânicas aos grãos por amassamento (Terasawa et al., 2009).

Em geral, para a realização da colheita mecanizada, é desejável que a umidade dos grãos atinja de 12 a $14 \%$. Grãos com umidade superior a $14 \%$ podem estar sujeitos à maior incidência de danos mecânicos latentes durante o processo de colheita, enquanto teores de umidade inferiores a $12 \%$ podem resultar em maior sensibilidade à quebra dos grãos e em prejuízos à qualidade fisiológica das sementes (França Neto et al., 2007).

No entanto, a associação entre a correta regulagem da altura de corte, o sistema de trilha, a velocidade da colhedora e a disponibilidade de uma estrutura de secagem eficiente permitem a realização da colheita mecanizada de grãos com teores de umidade superiores a 18\% (França Neto et al., 2007). Para Terasawa et al. (2009), a colheita mecanizada pode ser realizada com grãos com teores de umidade de até $22,9 \%$, o que maximiza a produção, sem ocasionar a perda da qualidade fisiológica das sementes de soja.

Há possibilidade de realização da colheita dos grãos com diferentes teores de umidade, graças ao desenvolvimento e à adição de tecnologias embarcadas nas novas colhedoras, tais como o uso de sensores de perda e regulagens elétricas (Schanoski et al., 2011; Oliveira et al., 2014). Assim, o operador pode monitorar diversos indicadores de qualidade, em tempo real, durante a colheita, e realizar os ajustes necessários para melhorar a eficiência no decorrer dessa operação (Cassia et al., 2015).

Contudo, a adoção de limiares mínimos ou máximos de umidade dos grãos, para a decisão sobre o início da colheita mecanizada, pode ser uma prática inadequada. Lacerda et al. (2003) descreveram a relação de dependência entre a umidade do grão e a precipitação pluvial, com ganho de sete pontos percentuais na ocorrência de aproximadamente $40 \mathrm{~mm}$ de precipitação, em intervalo de sete dias. A saturação de vapor de água na atmosfera, temperaturas superiores a $25^{\circ} \mathrm{C}$ e a precipitação pluvial, durante a pré-colheita da soja, influenciam diretamente o processo de perda e ganho de umidade dos grãos, o que resulta em lesões do tegumento da semente e em consequente decréscimo da produtividade e da qualidade fisiológica dos grãos (Marcandalli et al., 2011; Pádua et al., 2014).

Experimentos realizados em condições edafoclimáticas semelhantes avaliaram o efeito do atraso da colheita sobre a produtividade de grãos (Borges et al., 2006). Houve perdas significativas de produtividade, em consequência do atraso da colheita, influenciadas pela precipitação pluvial após o estádio R8 e pelas características genéticas de cada cultivar. Além das perdas de produtividade, o atraso da colheita pode acelerar o processo de deterioração da qualidade fisiológica das sementes de soja (Diniz et al., 2013b; Xavier et al., 2015).

Considerando-se os cenários futuros, caracterizados pela intensificação do uso do solo, adoção de cultivares de ciclo precoce e antecipação da semeadura e da colheita, associadas à ocorrência de eventos meteorológicos adversos, pode-se inferir que os problemas de perda de produção e qualidade de grãos, em razão do atraso da colheita, poderão ser mais frequentes. Uma forma complementar às práticas convencionais de planejamento da colheita pode ser o uso de modelos agrometeorológicos, que permite a redução das incertezas, durante o processo de tomada de decisões por parte dos agricultores e seus assistentes técnicos.

A partir da identificação dos modelos agrometeorológicos que melhor descrevem o comportamento da cultura da soja em uma determinada região, é possível utilizar algoritmos para a simulação da produtividade (Silva-Fuzzo et al., 2015; Klering et al., 2016), ou mesmo inseri-los em sistemas de apoio à decisão (Araujo et al., 2011).

O objetivo deste trabalho foi avaliar o efeito do atraso da colheita sobre a umidade dos grãos, massa de mil grãos e produtividade da soja, assim como identificar as variáveis agrometeorológicas mais importantes durante o período pré-colheita e propor algoritmos empíricos para a estimativa das perdas de produtividade.

\section{Material e Métodos}

Quatro experimentos foram realizados durante as safras 2011/2012 (uma época de semeadura), 2012/2013 (duas épocas) e 2013/2014 (uma época), no campo experimental de Castro, PR (2451'49"S, 49 56'08"W, à altitude de $1.109 \mathrm{~m}$ ), em Latossolo Vermelho distrófico típico, com textura argilosa, e clima $\mathrm{Cfb}$ segundo classificação climática de Köppen-Geiger. Outros três experimentos foram realizados em condições edafoclimáticas distintas, no campo experimental de Itaberá, $\mathrm{SP}\left(24^{\circ} 04^{\prime} \mathrm{S}, 49^{\circ} 09^{\prime} \mathrm{W}\right.$, à altitude de $\left.735 \mathrm{~m}\right)$, 
em Latossolo Vermelho-Escuro, com textura argilosa e clima Cfa, conforme classificação de Köppen-Geiger, durante a safra 2013/2014 (três épocas de semeadura), no total de sete ambientes avaliados com a cultivar de soja 'NA5909RG' (Tabela 1).

O sistema plantio direto, a rotação aveia-milhotrigo-soja, o espaçamento entre linhas de $0,4 \mathrm{~m}$, a população inicial de 30 plantas $\mathrm{m}^{-2}$ e a unidade experimental de $14 \mathrm{~m}^{2}$ (7 linhas de $5 \mathrm{~m}$ ) foram os critérios obedecidos em todos os ambientes. As sementes foram tratadas com fungicidas e inseticidas no dia da semeadura. Utilizaram-se $300 \mathrm{~kg} \mathrm{ha}^{-1}$ do formulado $\mathrm{N}-\mathrm{P}_{2} \mathrm{O}_{5}-\mathrm{K}_{2} \mathrm{O}$ 00-20-20. Os demais tratos culturais (controle de plantas daninhas, doenças e insetos-praga) foram realizados conforme recomendações técnicas.

$\mathrm{O}$ delineamento experimental em blocos ao acaso foi adotado para os sete ambientes, com o mínimo de quatro repetições. O efeito do atraso da colheita da soja foi medido por meio da realização da primeira colheita, no estádio fenológico R8.2 (DA8.2+0), caracterizado

Tabela 1. Caracterização dos ambientes (local, data de semeadura, número de tratamentos e repetições), onde foram avaliados o efeito do atraso da colheita após o estádio R8.2 (0, 7, 14, 21, 28, 35, 42 e 49 dias), sobre a cultivar 'NA5909RG', com os respectivos resultados das análises de variâncias individuais (Anava) para as variáveis umidade de grãos, massa de mil grãos, produtividade e respectivos valores relativos.

\begin{tabular}{|c|c|c|c|c|c|c|c|}
\hline Experimentos & Ambiente 1 & Ambiente 2 & Ambiente 3 & Ambiente 4 & Ambiente 5 & Ambiente 6 & Ambiente 7 \\
\hline Local & Castro, PR & Castro, PR & Castro, PR & Castro, PR & Itaberá, SP & Itaberá, SP & Itaberá, SP \\
\hline Semeadura & $16 / 12 / 2011$ & $21 / 11 / 2012$ & $3 / 12 / 2012$ & $20 / 12 / 2013$ & $30 / 10 / 2013$ & $18 / 11 / 2013$ & $12 / 12 / 2013$ \\
\hline Tratamentos & 8 & 8 & 8 & 8 & 8 & 8 & 8 \\
\hline \multirow[t]{2}{*}{ Repetições } & 4 & 5 & 5 & 5 & 5 & 5 & 5 \\
\hline & \multicolumn{7}{|c|}{ Umidade dos grãos (UMG, \%) } \\
\hline Média & 19,7 & 15,3 & 16,7 & 20,9 & 15,1 & 15,3 & 15,1 \\
\hline $\mathrm{QMR}^{(1)}$ & 0,57 & 0,27 & 0,41 & 0,20 & 0,34 & 0,05 & 0,02 \\
\hline REQM $^{(2)}$ & 0,75 & 0,52 & 0,64 & 0,45 & 0,59 & 0,23 & 0,16 \\
\hline \multirow[t]{2}{*}{ Prob $>F^{(3)}$} & $<0,0001$ & $<0,0001$ & $<0,0001$ & $<0,0001$ & $<0,0001$ & $<0,0001$ & $<0,0001$ \\
\hline & \multicolumn{7}{|c|}{ Umidade dos grãos relativa à primeira colheita (UMG.REL, \%) } \\
\hline Média & 83,4 & 121,4 & 96,2 & 87,9 & 106,7 & 91,2 & 118,7 \\
\hline QMR & 10,20 & 16,98 & 13,51 & 3,60 & 17,18 & 1,81 & 1,52 \\
\hline REQM & 3,19 & 4,12 & 3,68 & 1,90 & 4,14 & 1,34 & 1,23 \\
\hline \multirow{2}{*}{$\underline{\text { Prob }>\text { F }}$} & $<0,0001$ & $<0,0001$ & $<0,0001$ & $<0,0001$ & $<0,0001$ & $<0,0001$ & $<0,0001$ \\
\hline & \multicolumn{7}{|c|}{ Massa de mil grãos (MMG, g) } \\
\hline Média & 166,1 & 173,0 & 157,5 & 168,7 & 115,6 & 129,7 & 173,3 \\
\hline QMR & 47,06 & 19,59 & 14,05 & 25,72 & 34,68 & 18,63 & 25,69 \\
\hline REQM & 6,86 & 4,43 & 3,75 & 5,07 & 5,89 & 4,32 & 5,07 \\
\hline \multirow[t]{2}{*}{ Prob $>$ F } & 0,0250 & 0,0004 & 0,0100 & $<, 0001$ & 0,0894 & 0,2487 & 0,1503 \\
\hline & \multicolumn{7}{|c|}{ Massa de mil grãos relativo à primeira colheita (MMG.REL, \%) } \\
\hline Média & 97,9 & 104,4 & 103,6 & 102,5 & 102,4 & 100,9 & 98,7 \\
\hline QMR & 16,34 & 7,14 & 6,08 & 9,49 & 27,19 & 11,29 & 8,33 \\
\hline REQM & 4,04 & 2,67 & 2,47 & 3,08 & 5,21 & 3,36 & 2,89 \\
\hline \multirow[t]{2}{*}{ Prob $>F$} & 0,0250 & 0,0004 & 0,0100 & $<, 0001$ & 0,0894 & 0,2487 & 0,1503 \\
\hline & \multicolumn{7}{|c|}{ Produtividade de grãos (PG, $\left.\mathrm{kg} \mathrm{ha}^{-1}\right)$} \\
\hline Média & 3110,1 & 3729,3 & 3337,1 & 3099,5 & 2292,9 & 2851,9 & 3890,5 \\
\hline QMR & 89296,00 & 46189,00 & 47061,00 & 73656,00 & 134081,00 & 65962,00 & 61951,00 \\
\hline REQM & 298,82 & 214,92 & 216,94 & 271,40 & 366,17 & 256,83 & 248,90 \\
\hline \multirow[t]{2}{*}{$\underline{\text { Prob }>\text { F }}$} & 0,0001 & 0,0035 & $<0,0001$ & 0,0052 & 0,0024 & $<0,0001$ & 0,0192 \\
\hline & \multicolumn{7}{|c|}{ Produtividade de grãos relativa à primeira colheita (PG.REL, \%) } \\
\hline Média & 86,6 & 103,5 & 93,0 & 89,5 & 79,0 & 95,2 & 104,1 \\
\hline QMR & 69,27 & 35,54 & 36,56 & 61,36 & 159,27 & 73,43 & 44,33 \\
\hline REQM & 8,32 & 5,96 & 6,05 & 7,83 & 12,62 & 8,57 & 6,66 \\
\hline Prob $>$ F & 0,0001 & 0,0035 & $<0,0001$ & 0,0052 & 0,0024 & $<0,0001$ & 0,0192 \\
\hline
\end{tabular}

${ }^{(1)}$ Quadrado médio do resíduo. ${ }^{(2)}$ Raiz do erro quadrático médio. ${ }^{(3)}$ Probabilidade de significância. 
visualmente pela desfolha igual ou superior a $50 \%$ das plantas (Câmara, 2006). Os demais tratamentos consistiram de colheitas realizadas a intervalos de 7 , 14, 21, 28, 35, 42 e 49 dias após o estádio R8.2.

A colheita de todos os experimentos foi realizada manualmente, para posterior medida da percentagem de umidade do grão (UMG) e massa de mil grãos em gramas (MMG), de acordo com as Regras de análise de sementes (Brasil, 2009), produtividade de grãos $\left(\mathrm{PG}, \mathrm{kg} \mathrm{ha}^{-1}\right)$, por meio da colheita de quatro linhas centrais de $4 \mathrm{~m}$, posterior trilha mecânica e correção da umidade para a base de $13 \%$. Foram também calculados os valores relativos para estas mesmas variáveis (UMG.REL, MMG.REL e PG.REL), pela divisão do valor da variável de interesse da colheita, realizada aos 7, 14, 21, 28, 35, 42 e 49 dias, pelo valor obtido da colheita de soja no dia 0 (estádio R8.2).

Para o monitoramento das condições meteorológicas, instalaram-se sensores de temperatura e umidade relativa do ar, modelo HygroClipS3 (Rotronic AG, Bassersdorf, Zurique, Suiça), radiação solar global, modelo LI-200X (Li-Cor, Lincoln, NE, EUA), velocidade e direção do vento a 2,0 $\mathrm{m}$ de altura, modelo 3002 (Young, Traverse, MI, EUA) e pluviômetro de báscula, com resolução de $0,245 \mathrm{~mm}$, modelo ECRN-100 (Decagon, Hopkins, MN, EUA). Estes sensores foram acoplados a uma plataforma de coleta de dados, com leitura a intervalos de $60 \mathrm{~s}$, e aquisição de dados médios, máximos, mínimos e totais a intervalos de $15 \mathrm{~min}$. Os registros agrometeorológicos para os sete ambientes estudados foram sumarizados no período de 10 dias antes do estádio R8.2 até a data da colheita de cada tratamento.

As médias das variáveis respostas foram submetidas aos testes de Levene e de Shapiro-Wilk, para determinar a homocedasticidade das variâncias e a normalidade dos erros. Em seguida, as médias foram submetidas aos testes de média e à análise de regressão. Os erros das variáveis respostas que não atenderam às pressuposições básicas foram transformados pelo método de Box-Cox. A pressuposição de homogeneidade das variâncias residuais dos experimentos também foi verificada pelo teste de Hartley, citado por Pimentel-Gomes \& Garcia (2002), para a realização da análise de variância em grupo de experimentos, com o objetivo de avaliar o efeito da interação entre os fatores ambiente (AMB) e o atraso da colheita (DA8.2), para as variáveis UMG, MMG e PG.

\section{Resultados e Discussão}

Em geral, o ambiente 4 apresentou o maior volume acumulado de precipitação pluvial $(327,6 \mathrm{~mm})$ e a menor média de radiação solar global $\left(11,7 \mathrm{MJ} \mathrm{m}^{-2}\right.$ por dia), porém, o ambiente 1 registrou a maior média de umidade relativa do ar $(90,9 \%)$, durante o período entre 0 e 49 dias após o R8.2 (Figura 1). Condições meteorológicas opostas foram observadas nos ambientes 5, 6 e 7, com maiores valores de radiação solar global, menores médias da umidade relativa do ar, além da superioridade das temperaturas máximas e mínimas.

Mesmo em condições meteorologicamente contrastantes, foi possível a inclusão de todos os ambientes na análise em grupo de experimentos para a massa de mil grãos (MMG) e produtividade de grãos (PG), enquanto, para a umidade dos grãos (UMG), houve necessidade de exclusão dos ambientes 6 e 7 . Houve interação significativa entre os fatores ambiente (AMB) e atraso da colheita após o estádio de R8.2 (DA8.2) para todas as variáveis avaliadas.

As colheitas realizadas a intervalos de sete dias evidenciaram a perda alternada com a elevação da umidade dos grãos, em todos os sete ambientes avaliados (Tabela 2). A maior amplitude entre os valores de umidade foi registrada no ambiente 4 , e foram observados ganhos de $10,2 \%$ entre as colheitas realizadas aos 21 e 28 dias após o estádio R8.2 (119,4 mm de precipitação pluvial, distribuídos em cinco eventos), mas também perdas de $26,3 \%$ para $18,3 \%$ na colheita seguinte, realizada aos 35 dias após $\mathrm{R} 8.2$, quando foram registrados $4,4 \mathrm{~mm}$ distribuídos em dois eventos de precipitação. A regressão linear entre a umidade relativa dos grãos e o número de dias com precipitação pluvial igual ou maior do que $3 \mathrm{~mm}$ resultou em coeficiente de determinação ajustado $\left(\mathrm{R}^{2}\right.$ ajustado $)=0,28$ e nível descritivo do teste $(\mathrm{p} \leq 0,0001)$ (Figura $2 \mathrm{~A}$ ).

Lacerda et al. (2003) relataram a relação de dependência entre a umidade do grão da soja e a precipitação pluvial, com decréscimo de 21 para $11 \%$, na ausência de precipitação durante os sete dias após a aplicação de dessecante foliar, assim como a elevação da umidade dos grãos para $18 \%$ aos 14 dias, em razão da incidência de aproximadamente $30 \mathrm{~mm}$.

A relação entre a variação da umidade dos grãos de soja e a ausência da precipitação pluvial também foi relatada por Marcondes et al. (2005) quando, 


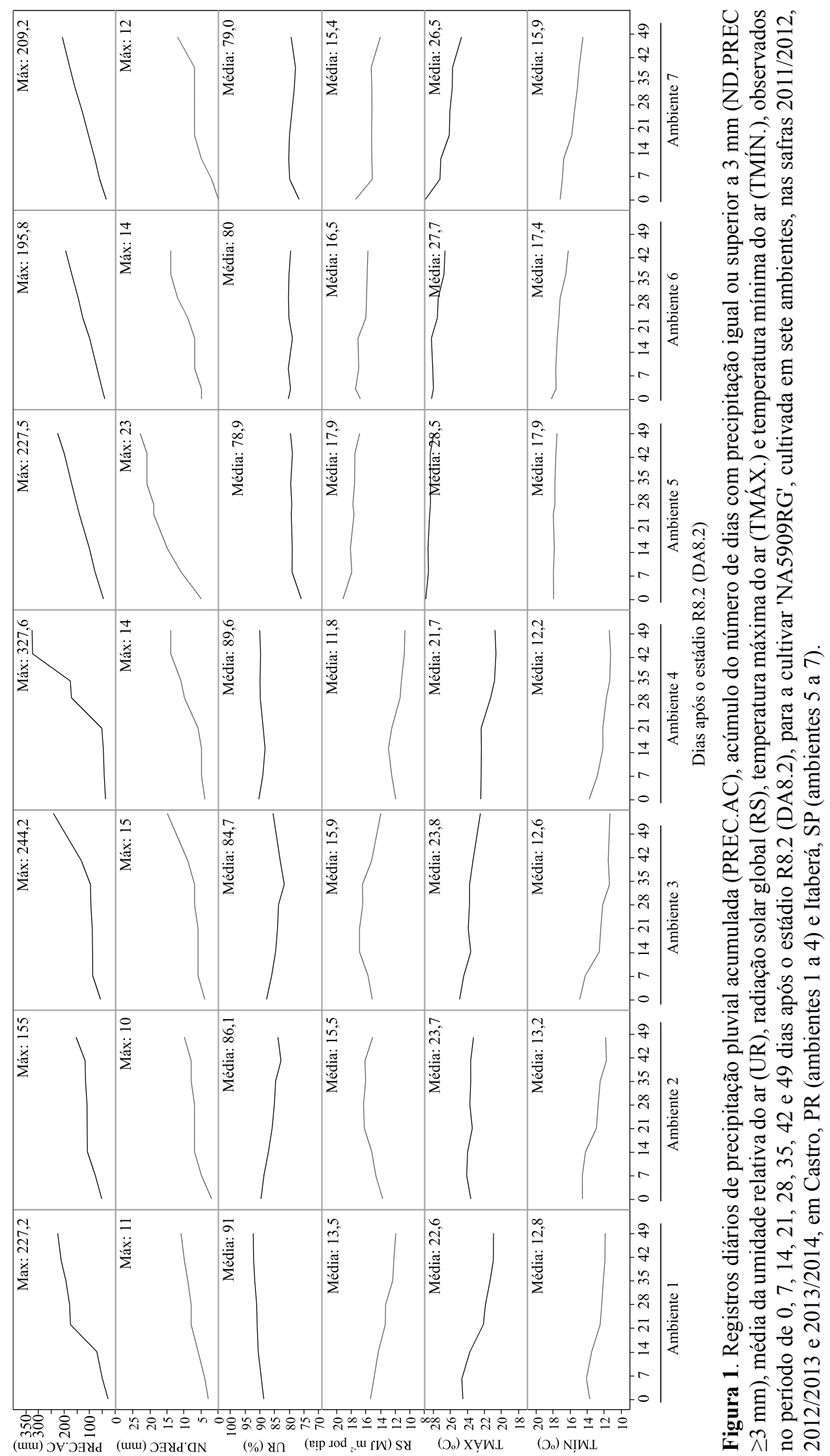

Pesq. agropec. bras., Brasília, v.51, n.8, p.905-915, ago. 2016 DOI: 10.1590/S0100-204X2016000800002 
Tabela 2. Interação entre ambiente e atraso da colheita, após o estádio fenológico R8.2 (DA8.2) da soja, sobre a umidade de grãos (UMG), massa de mil grãos (MMG), produtividade e seus respectivos valores relativos (UMG.REL, MMG.REL e PG.REL), para a cultivar 'NA5909RG', em 7 ambientes, safras 2011/2012, 2012/2013 e 2013/2014, em Castro, PR e Itaberá, SP(1).

\begin{tabular}{|c|c|c|c|c|c|c|}
\hline $\begin{array}{l}\text { DA8.2(2) } \\
\text { (dias) }\end{array}$ & $\begin{array}{c}\text { Umidade de grãos } \\
(\%)\end{array}$ & $\begin{array}{c}\text { Massa de mil grãos } \\
(\mathrm{g})\end{array}$ & $\begin{array}{l}\text { Produtividade de } \\
\text { grãos }\left(\mathrm{kg} \mathrm{ha}^{-1}\right)\end{array}$ & $\begin{array}{l}\text { UMG.REL } \\
(\%)\end{array}$ & $\begin{array}{c}\text { MMG.REL } \\
(\%)\end{array}$ & $\begin{array}{c}\text { PG.REL } \\
(\%)\end{array}$ \\
\hline 0 & $45,9 \mathrm{~A}$ & $153,9 \mathrm{~B}$ & $3.135 \mathrm{~A}$ & $100,0 \mathrm{~F}$ & $100,0 \mathrm{~A}$ & $100,0 \mathrm{~A}$ \\
\hline 7 & $19,7 \mathrm{D}$ & $148,3 \mathrm{~B}$ & $3.219 \mathrm{~A}$ & $42,9 \mathrm{~K}$ & $96,4 \mathrm{~A}$ & $102,7 \mathrm{~A}$ \\
\hline 14 & $17,4 \mathrm{~F}$ & $146,6 \mathrm{~B}$ & $3.174 \mathrm{~A}$ & $37,9 \mathrm{~K}$ & $95,3 \mathrm{~A}$ & $101,2 \mathrm{~A}$ \\
\hline 21 & $18,8 \mathrm{E}$ & $145,5 \mathrm{~B}$ & $2.979 \mathrm{~B}$ & $40,9 \mathrm{~K}$ & $94,5 \mathrm{~A}$ & $95,0 \mathrm{~A}$ \\
\hline 28 & $17,9 \mathrm{E}$ & $148,2 \mathrm{~B}$ & $2.991 \mathrm{~B}$ & $39,0 \mathrm{~K}$ & $96,3 \mathrm{~A}$ & $95,4 \mathrm{~A}$ \\
\hline 35 & $24,3 \mathrm{C}$ & $158,5 \mathrm{~B}$ & $2.968 \mathrm{~B}$ & $53,0 \mathrm{~J}$ & $103,0 \mathrm{~A}$ & $94,7 \mathrm{~A}$ \\
\hline 42 & $19,5 \mathrm{E}$ & $148,8 \mathrm{~B}$ & $2.680 \mathrm{~B}$ & $42,5 \mathrm{~K}$ & $96,7 \mathrm{~A}$ & $85,5 \mathrm{~B}$ \\
\hline \multirow[t]{2}{*}{49} & $19,0 \mathrm{E}$ & $154,7 \mathrm{~B}$ & $2.620 \mathrm{~B}$ & $41,3 \mathrm{~K}$ & $100,5 \mathrm{~A}$ & $83,6 \mathrm{~B}$ \\
\hline & \multicolumn{6}{|c|}{ Ambiente 2} \\
\hline 0 & $12,3 \mathrm{G}$ & $165,0 \mathrm{~A}$ & $3.630 \mathrm{~A}$ & $97,3 \mathrm{~F}$ & $99,6 \mathrm{~A}$ & $100,7 \mathrm{~A}$ \\
\hline 7 & $13,2 \mathrm{G}$ & $169,8 \mathrm{~A}$ & $3.835 \mathrm{~A}$ & $104,9 \mathrm{E}$ & $102,5 \mathrm{~A}$ & $106,4 \mathrm{~A}$ \\
\hline 14 & $12,5 \mathrm{G}$ & $168,5 \mathrm{~A}$ & $3.891 \mathrm{~A}$ & $98,7 \mathrm{~F}$ & $101,7 \mathrm{~A}$ & $107,9 \mathrm{~A}$ \\
\hline 21 & $19,0 \mathrm{E}$ & $174,3 \mathrm{~A}$ & $3.953 \mathrm{~A}$ & $150,7 \mathrm{~B}$ & $105,3 \mathrm{~A}$ & $109,7 \mathrm{~A}$ \\
\hline 28 & $14,1 \mathrm{G}$ & $175,8 \mathrm{~A}$ & $3.919 \mathrm{~A}$ & $111,7 \mathrm{E}$ & $106,1 \mathrm{~A}$ & $108,7 \mathrm{~A}$ \\
\hline 35 & $16,1 \mathrm{~F}$ & $177,4 \mathrm{~A}$ & $3.638 \mathrm{~A}$ & $127,4 \mathrm{C}$ & $107,1 \mathrm{~A}$ & $100,9 \mathrm{~A}$ \\
\hline 42 & $14,7 \mathrm{G}$ & $174,8 \mathrm{~A}$ & $3.488 \mathrm{~A}$ & $116,1 \mathrm{D}$ & $105,5 \mathrm{~A}$ & $96,8 \mathrm{~A}$ \\
\hline \multirow[t]{2}{*}{49} & \multirow{2}{*}{\multicolumn{6}{|c|}{ Ambiente 3}} \\
\hline & & & & & & \\
\hline 0 & $17,3 \mathrm{~F}$ & $152,1 \mathrm{~B}$ & $3.588 \mathrm{~A}$ & $100,0 \mathrm{~F}$ & $100,0 \mathrm{~A}$ & $100,0 \mathrm{~A}$ \\
\hline 7 & $12,6 \mathrm{G}$ & $158,5 \mathrm{~B}$ & $3.596 \mathrm{~A}$ & $72,8 \mathrm{I}$ & $104,2 \mathrm{~A}$ & $100,2 \mathrm{~A}$ \\
\hline 14 & $18,8 \mathrm{E}$ & $157,1 \mathrm{~B}$ & $3.574 \mathrm{~A}$ & $108,4 \mathrm{E}$ & $103,3 \mathrm{~A}$ & $99,6 \mathrm{~A}$ \\
\hline 21 & $14,0 \mathrm{G}$ & $155,0 \mathrm{~B}$ & $3.383 \mathrm{~A}$ & $80,7 \mathrm{H}$ & $101,9 \mathrm{~A}$ & $94,3 \mathrm{~A}$ \\
\hline 28 & $16,3 \mathrm{~F}$ & $159,6 \mathrm{~B}$ & $3.264 \mathrm{~A}$ & $94,3 \mathrm{~F}$ & $105,0 \mathrm{~A}$ & $91,0 \mathrm{~B}$ \\
\hline 35 & $14,7 \mathrm{G}$ & $158,7 \mathrm{~B}$ & $3.479 \mathrm{~A}$ & $84,6 \mathrm{G}$ & $104,3 \mathrm{~A}$ & $97,0 \mathrm{~A}$ \\
\hline 42 & $21,5 \mathrm{D}$ & $162,2 \mathrm{~B}$ & $3.184 \mathrm{~A}$ & $124,0 \mathrm{C}$ & $106,7 \mathrm{~A}$ & $88,7 \mathrm{~B}$ \\
\hline \multirow[t]{2}{*}{49} & $18,1 \mathrm{E}$ & $156,7 \mathrm{~B}$ & $2.628 \mathrm{~B}$ & $104,6 \mathrm{E}$ & $103,0 \mathrm{~A}$ & $73,3 \mathrm{~B}$ \\
\hline & \multicolumn{6}{|c|}{ Ambiente 4} \\
\hline 0 & $23,7 \mathrm{C}$ & $164,6 \mathrm{~A}$ & $3.465 \mathrm{~A}$ & $100,0 \mathrm{~F}$ & $100,0 \mathrm{~A}$ & $100,0 \mathrm{~A}$ \\
\hline 7 & $20,7 \mathrm{D}$ & $167,3 \mathrm{~A}$ & $3.043 \mathrm{~B}$ & $87,2 \mathrm{G}$ & $101,6 \mathrm{~A}$ & $87,8 \mathrm{~B}$ \\
\hline 14 & $16,6 \mathrm{~F}$ & $164,3 \mathrm{~A}$ & $3.342 \mathrm{~A}$ & $70,1 \mathrm{I}$ & $99,8 \mathrm{~A}$ & $96,5 \mathrm{~A}$ \\
\hline 21 & $16,0 \mathrm{~F}$ & $163,3 \mathrm{~A}$ & $3.289 \mathrm{~A}$ & $67,5 \mathrm{I}$ & $99,2 \mathrm{~A}$ & $94,9 \mathrm{~A}$ \\
\hline 28 & $26,3 \mathrm{~B}$ & $181,8 \mathrm{~A}$ & $2.892 \mathrm{~B}$ & $110,9 \mathrm{E}$ & $110,4 \mathrm{~A}$ & $83,5 \mathrm{~B}$ \\
\hline 35 & $18,3 \mathrm{E}$ & $163,5 \mathrm{~A}$ & $2.944 \mathrm{~B}$ & $77,3 \mathrm{H}$ & $99,3 \mathrm{~A}$ & $85,0 \mathrm{~B}$ \\
\hline 42 & $25,3 \mathrm{~B}$ & $176,8 \mathrm{~A}$ & $3.011 \mathrm{~B}$ & $106,5 \mathrm{E}$ & $107,4 \mathrm{~A}$ & $86,9 \mathrm{~B}$ \\
\hline \multirow[t]{2}{*}{49} & $19,9 \mathrm{D}$ & $167,7 \mathrm{~A}$ & $2.811 \mathrm{~B}$ & $83,8 \mathrm{G}$ & $101,9 \mathrm{~A}$ & $81,1 \mathrm{~B}$ \\
\hline & \multicolumn{6}{|c|}{ Ambiente 5} \\
\hline 0 & $14,2 \mathrm{G}$ & $112,9 \mathrm{D}$ & $2.901 \mathrm{~B}$ & $100,0 \mathrm{~F}$ & $100,0 \mathrm{~A}$ & $100,0 \mathrm{~A}$ \\
\hline 7 & $18,6 \mathrm{E}$ & $110,4 \mathrm{D}$ & $2.562 \mathrm{~B}$ & $131,2 \mathrm{C}$ & $97,7 \mathrm{~A}$ & $88,3 \mathrm{~B}$ \\
\hline 14 & $13,4 \mathrm{G}$ & $116,7 \mathrm{D}$ & $2.323 \mathrm{C}$ & $94,6 \mathrm{~F}$ & $103,3 \mathrm{~A}$ & $80,1 \mathrm{~B}$ \\
\hline 21 & $16,7 \mathrm{~F}$ & $117,0 \mathrm{D}$ & $2.362 \mathrm{C}$ & $117,9 \mathrm{D}$ & $103,6 \mathrm{~A}$ & $81,4 \mathrm{~B}$ \\
\hline 28 & $13,7 \mathrm{G}$ & $112,0 \mathrm{D}$ & $2.188 \mathrm{C}$ & $96,5 \mathrm{~F}$ & $99,1 \mathrm{~A}$ & $75,4 \mathrm{~B}$ \\
\hline 35 & $16,7 \mathrm{~F}$ & $115,4 \mathrm{D}$ & $2.236 \mathrm{C}$ & $117,8 \mathrm{D}$ & $102,1 \mathrm{~A}$ & $77,1 \mathrm{~B}$ \\
\hline 42 & $13,4 \mathrm{G}$ & $120,6 \mathrm{D}$ & $1.971 \mathrm{C}$ & $94,4 \mathrm{~F}$ & $106,7 \mathrm{~A}$ & $67,9 \mathrm{~B}$ \\
\hline \multirow[t]{2}{*}{49} & $14,3 \mathrm{G}$ & $120,3 \mathrm{D}$ & $1.799 \mathrm{C}$ & $101,0 \mathrm{~F}$ & $106,5 \mathrm{~A}$ & $62,0 \mathrm{~B}$ \\
\hline & \multicolumn{6}{|c|}{ Ambiente 6} \\
\hline 0 & - & $128,5 \mathrm{C}$ & $2.997 \mathrm{~B}$ & - & $100,0 \mathrm{~A}$ & $100,0 \mathrm{~A}$ \\
\hline 7 & - & $124,9 \mathrm{C}$ & $3.247 \mathrm{~A}$ & ـ & $97,2 \mathrm{~A}$ & $108,3 \mathrm{~A}$ \\
\hline 14 & - & $131,4 \mathrm{C}$ & $3.326 \mathrm{~A}$ & - & $102,3 \mathrm{~A}$ & $111,0 \mathrm{~A}$ \\
\hline 21 & - & $129,8 \mathrm{C}$ & $2.833 \mathrm{~B}$ & - & $101,0 \mathrm{~A}$ & $94,5 \mathrm{~A}$ \\
\hline 28 & - & $129,6 \mathrm{C}$ & $2.730 \mathrm{~B}$ & - & $100,9 \mathrm{~A}$ & $91,1 \mathrm{~B}$ \\
\hline 35 & - & $130,1 \mathrm{C}$ & $2.571 \mathrm{~B}$ & - & $101,3 \mathrm{~A}$ & $85,8 \mathrm{~B}$ \\
\hline 42 & - & $132,3 \mathrm{C}$ & $2.379 \mathrm{C}$ & - & $102,9 \mathrm{~A}$ & $79,4 \mathrm{~B}$ \\
\hline \multirow[t]{2}{*}{49} & - & $130,9 \mathrm{C}$ & $2.731 \mathrm{~B}$ & - & $101,9 \mathrm{~A}$ & $91,1 \mathrm{~B}$ \\
\hline & \multicolumn{6}{|c|}{ Ambiente 7} \\
\hline 0 & - & $175,6 \mathrm{~A}$ & $3.738 \mathrm{~A}$ & - & $100,0 \mathrm{~A}$ & $100,0 \mathrm{~A}$ \\
\hline 7 & - & $172,8 \mathrm{~A}$ & $3.987 \mathrm{~A}$ & - & $98,4 \mathrm{~A}$ & $106,6 \mathrm{~A}$ \\
\hline 14 & - & $171,1 \mathrm{~A}$ & $4.018 \mathrm{~A}$ & - & $97,4 \mathrm{~A}$ & $107,5 \mathrm{~A}$ \\
\hline 21 & - & $173,6 \mathrm{~A}$ & $3.877 \mathrm{~A}$ & - & $98,9 \mathrm{~A}$ & $103,7 \mathrm{~A}$ \\
\hline 28 & - & $174,2 \mathrm{~A}$ & $4.116 \mathrm{~A}$ & - & $99,2 \mathrm{~A}$ & $110,1 \mathrm{~A}$ \\
\hline 35 & - & $178,2 \mathrm{~A}$ & $3.881 \mathrm{~A}$ & - & $101,5 \mathrm{~A}$ & $103,8 \mathrm{~A}$ \\
\hline 42 & - & $168,3 \mathrm{~A}$ & $3.997 \mathrm{~A}$ & - & $95,9 \mathrm{~A}$ & $106,9 \mathrm{~A}$ \\
\hline 49 & - & $172,4 \mathrm{~A}$ & $3.510 \mathrm{~A}$ & - & $98,2 \mathrm{~A}$ & $93,9 \mathrm{~A}$ \\
\hline$\overline{\text { Prob }>F}$ & & $<0,0001$ & 0,0003 & $<0,0001$ & $<0,0001$ & 0,0002 \\
\hline Média & 18,0 & 152,7 & 3.173 & 94,1 & 101,6 & 94,1 \\
\hline CV (\%) & 30,3 & 14,4 & 19,7 & 30,9 & 4,7 & 14,7 \\
\hline
\end{tabular}

${ }^{(1)}$ Médias seguidas de letras iguais, nas colunas, não diferem pelo teste de Scott-Knott, a $5 \%$ de probabilidade. (2) Tabela de interação com dupla entrada (AMB e DA8.2) foi adaptada para apresentação das comparações em uma única coluna. CV, coeficiente de variação. (-) Não atendeu os pressupostos da análise de variância em grupo de experimentos, segundo o teste de Hartley. 
independentemente do tipo de trilha avaliado (cilindro côncavo ou axial), houve variação de até $3 \%$ da umidade dos grãos em um intervalo de oito horas sem precipitação, dentro do mesmo dia e local de estudo. Entretanto, observaram-se melhor índice de pureza, menor perda total e menor índice de dano mecânico em colhedoras, com a tecnologia axial de trilha, em condições de umidade dos grãos de soja entre 18 e $21 \%$ (Camolese et al., 2015).

Quanto à massa de mil grãos (Tabela 2), os menores valores foram observados no ambiente 5 . Não houve efeito significativo do fator atraso de colheita, o que
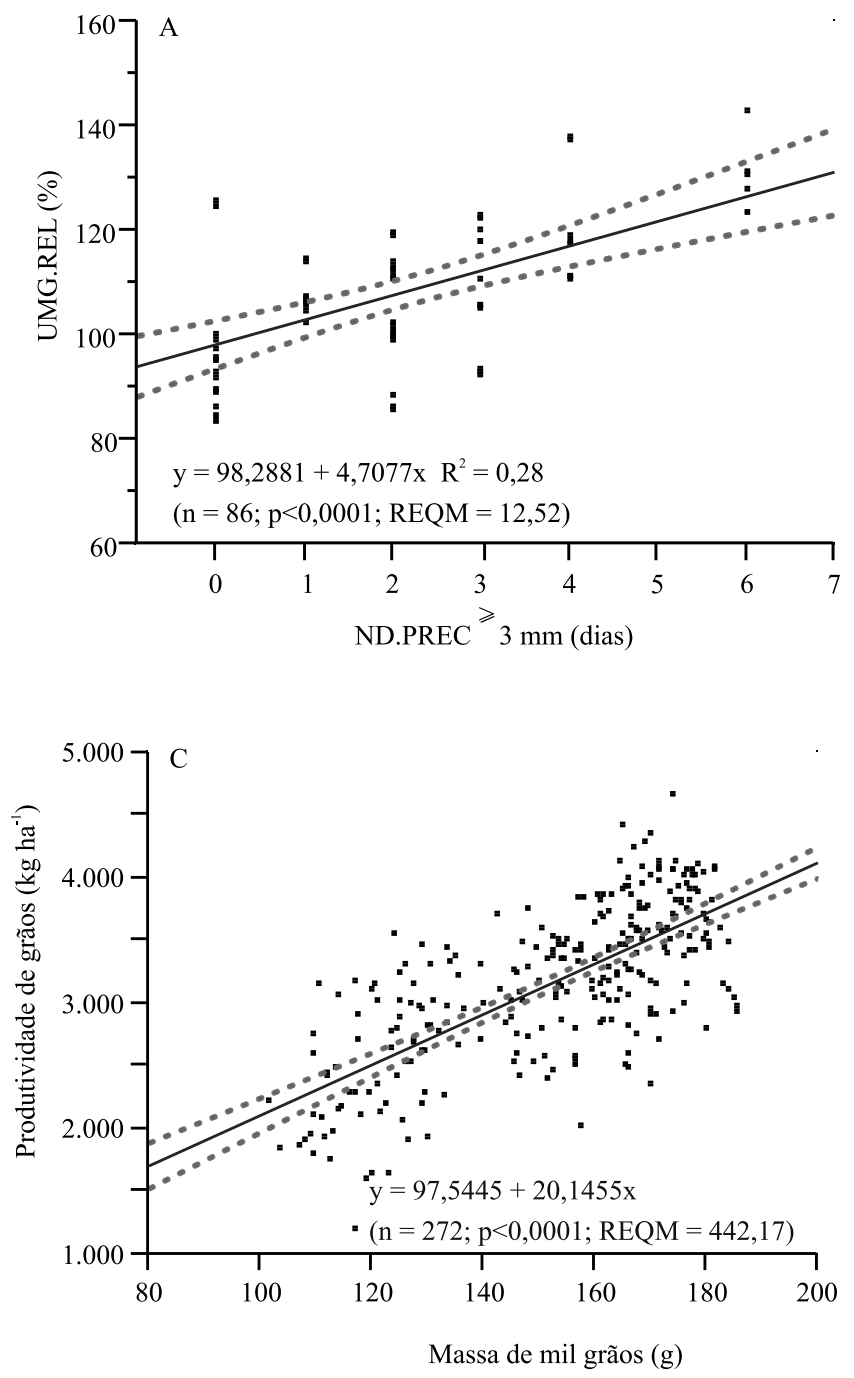

também foi observado com colheita 20 dias após o R8 (Gris et al., 2010). A análise de regressão com a umidade dos grãos apresentou tendência linear e direta, com $\mathrm{R}^{2}=0,11$ e $\mathrm{p}$ valor $\leq 0,0001$ (Figura $2 \mathrm{~B}$ ). Em estudos realizados em laboratório, com adição de água destilada e repouso dos grãos de soja por 72 horas, Davies \& El-Okene (2009) obtiveram uma relação direta e linear com a massa de mil grãos.

Dada a relação de dependência entre a umidade dos grãos e o número de dias com precipitação pluvial, e entre a umidade e a massa de mil grãos, constatou-se também a correlação linear e direta da produtividade de
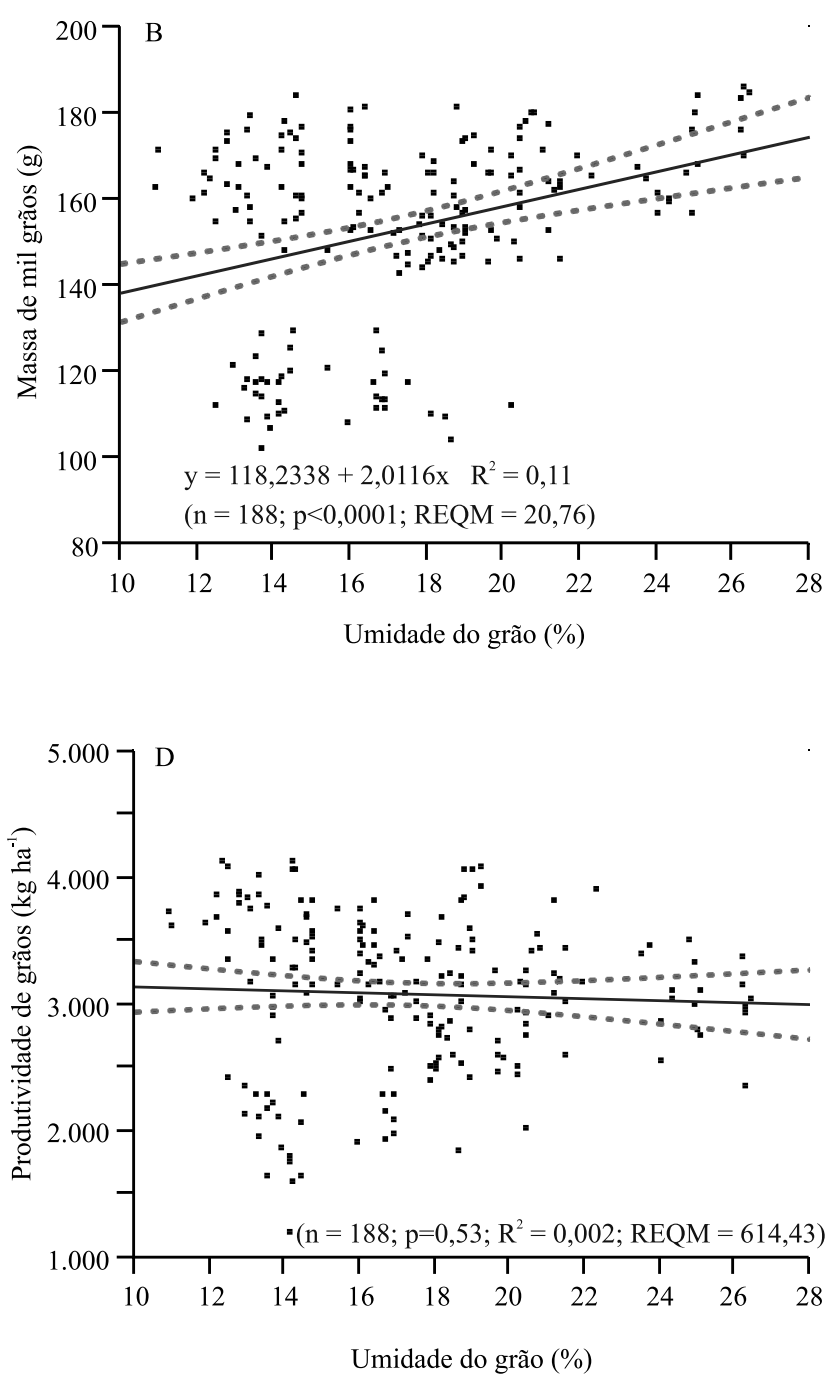

Figura 2. Relação entre: $A$, número de dias com precipitação pluvial $\geq 3 \mathrm{~mm}$ (ND.PREC $\geq 3 \mathrm{~mm}$ ) e umidade relativa do grão (UMG.REL); B, umidade do grão e massa de mil grãos; $\mathrm{C}$, massa de mil grãos e produtividade de grãos; $\mathrm{D}$, umidade do grão e produtividade de grãos. Cultivar 'NA5909RG', em sete ambientes, nas safras 2011/2012, 2012/2013 e 2013/2014, em Castro, PR e Itaberá, SP. 
grãos com a massa de mil grãos de soja, com $\mathrm{R}^{2}=0,50$ e $\mathrm{p} \leq 0,0001$ (Figura $2 \mathrm{C}$ ). Contudo, a produtividade de grãos não apresentou relação significativa com a umidade de grãos (Figura 2 D).

$\mathrm{O}$ ambiente 5 apresentou as maiores perdas de produtividade aos 49 dias após o estádio R8.2 (1.102 $\mathrm{kg} \mathrm{ha}^{-1}$ ), justificadas pela distribuição da precipitação pluvial (23 dias com precipitação $\geq 3 \mathrm{~mm}$ ), altas taxas de radiação solar global $\left(17,8 \mathrm{MJ} \mathrm{m}^{-2}\right.$ $\left.\mathrm{dia}^{-1}\right)$ e temperaturas máximas elevadas $\left(28,5^{\circ} \mathrm{C}\right)$, nesse mesmo período. No entanto, as menores perdas de produtividade foram registradas no ambiente 2 (150 $\mathrm{kg} \mathrm{ha}^{-1}$ ), caracterizado pela menor quantidade de dias com precipitação (10 dias com precipitação $\geq 3 \mathrm{~mm})$, menor acúmulo de precipitação $(155 \mathrm{~mm}) \mathrm{e}$ baixas temperaturas (máxima de $23,7^{\circ} \mathrm{C}$ e mínima de $\left.13,2^{\circ} \mathrm{C}\right)$.

Durante a safra de 2001/2002, em Ponta Grossa, PR, ocorreram perdas médias de produtividade da ordem de $1.826 \mathrm{~kg} \mathrm{ha}^{-1}$ de quatro cultivares de soja, após 45 dias de atraso da colheita (Borges et al., 2006).

Os genótipos que não apresentam a enzima lipoxigenase, mostram melhor qualidade fisiológica de sementes após o retardamento da colheita (Lima et al., 2007). Em condições de chuva artificial, no período pré-colheita, observou-se a melhor qualidade fisiológica e a menor percentagem de dano em cultivares com maior teor de lignina (Castro et al., 2016). Contudo, é possível que haja outros fatores intrínsecos ao genótipo, que podem conferir maior qualidade em situações de atraso da colheita da soja (Carvalho et al., 2014).

A partir das médias de produtividade relativa de grãos (PG.REL), calculadas por tratamento $(n=56)$, ajustou-se uma equação de regressão quadrática com $\mathrm{R}^{2}$ ajustado $=0,32$ e raiz do erro quadrático médio $($ REQM $)=9,36 \%$ (Figura 3). Considerando-se a produtividade de $4.000 \mathrm{~kg} \mathrm{ha}^{-1}$, estimaram-se perdas médias de produtividade de soja de até 4,9, 7,5, $10,1,12,8,15,4,18,1,20,7,23,4,26,0$ ou $28,7 \%$, em situações de atraso de $5,10,15,20,25,30,35,40,45$ ou 50 dias após o estádio R8.2, respectivamente.

Além da perda de produtividade de soja, em razão do atraso da colheita após o estádio R8.2, a redução qualitativa dos parâmetros fisiológicos pode ser atribuída ao processo respiratório das sementes que, por sua vez, pode ser favorecido em situações de precipitações pluviais frequentes durante o período pré-colheita (Minuzzi et al., 2010). Condições meteorológicas desfavoráveis na pré-colheita, como o excesso de chuva nos períodos de 14, 21 e 28 dias após o estádio R7, podem contribuir de forma significativa para a deterioração da qualidade fisiológica das sementes (Carraro et al., 1985). O atraso da colheita também pode intensificar a ação de fungos como Fusarium spp., Phomopsis spp. e Epicoccum spp., que podem promover a deterioração das sementes (Diniz et al., 2013a).

Dois algoritmos para a estimativa da produtividade relativa de grãos (PG.REL) foram propostos, assim que se observou a tendência de decréscimo da produtividade de soja, em situações de atraso da colheita, principalmente quando associada a condições meteorológicas desfavoráveis (precipitação pluvial frequente, alta umidade relativa do ar, baixas taxas de radiação solar). A escolha das variáveis independentes baseou-se na facilidade de obtenção das variáveis agrometeorológicas e nos valores resultantes do teste parcial $\mathrm{F}$ e do parâmetro REQM da análise de regressão pelo método stepwise.

O primeiro algoritmo fez uso de apenas uma variável agrometeorológica, de fácil obtenção em

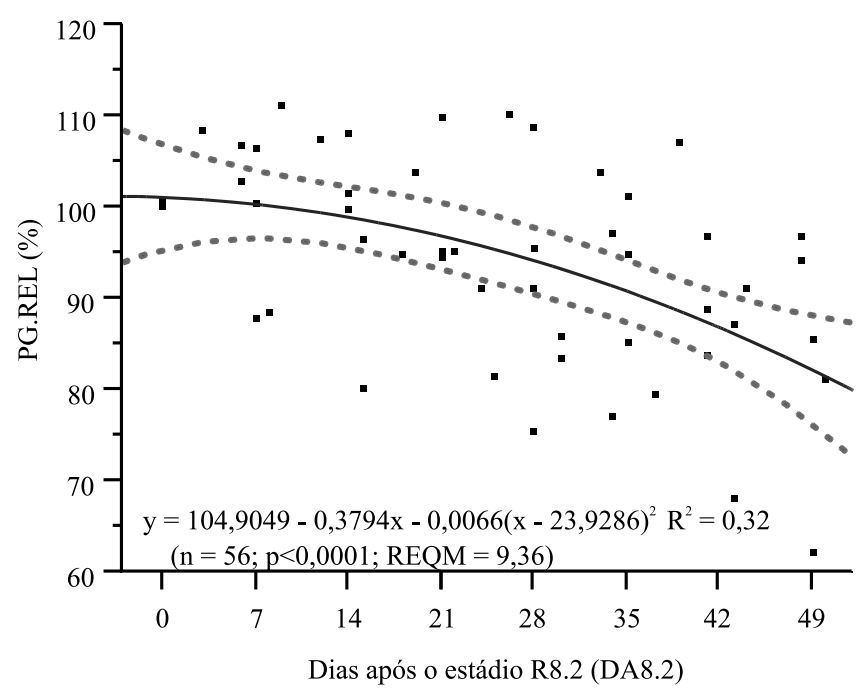

Figura 3. Estimativa das perdas relativas diárias de produtividade (PG.REL), em função do número de dias após o estágio fenológico de R8.2 da soja, por meio de um modelo de regressão quadrático. ${ }^{(-)}$Linha contínua preta, valores preditos. ${ }^{(-)}$Linha pontilhada cinza, intervalo de confiança de $95 \%$ de probabilidade. Cultivar 'NA5909RG', em sete ambientes, nas safras 2011/2012, 2012/2013 e 2013/2014, em Castro, PR e Itaberá, SP. 
postos pluviométricos convencionais ou automáticos, denominada número de dias com precipitação pluvial igual ou superior a $3 \mathrm{~mm}$ (ND.PREC $\geq 3 \mathrm{~mm}$ ), com $\mathrm{R}^{2}=0,69$ e $\mathrm{REQM}=6,25 \%$ (Figura $4 \mathrm{~A}$ ). Para cada dia com precipitação igual ou superior a $3 \mathrm{~mm}$ após
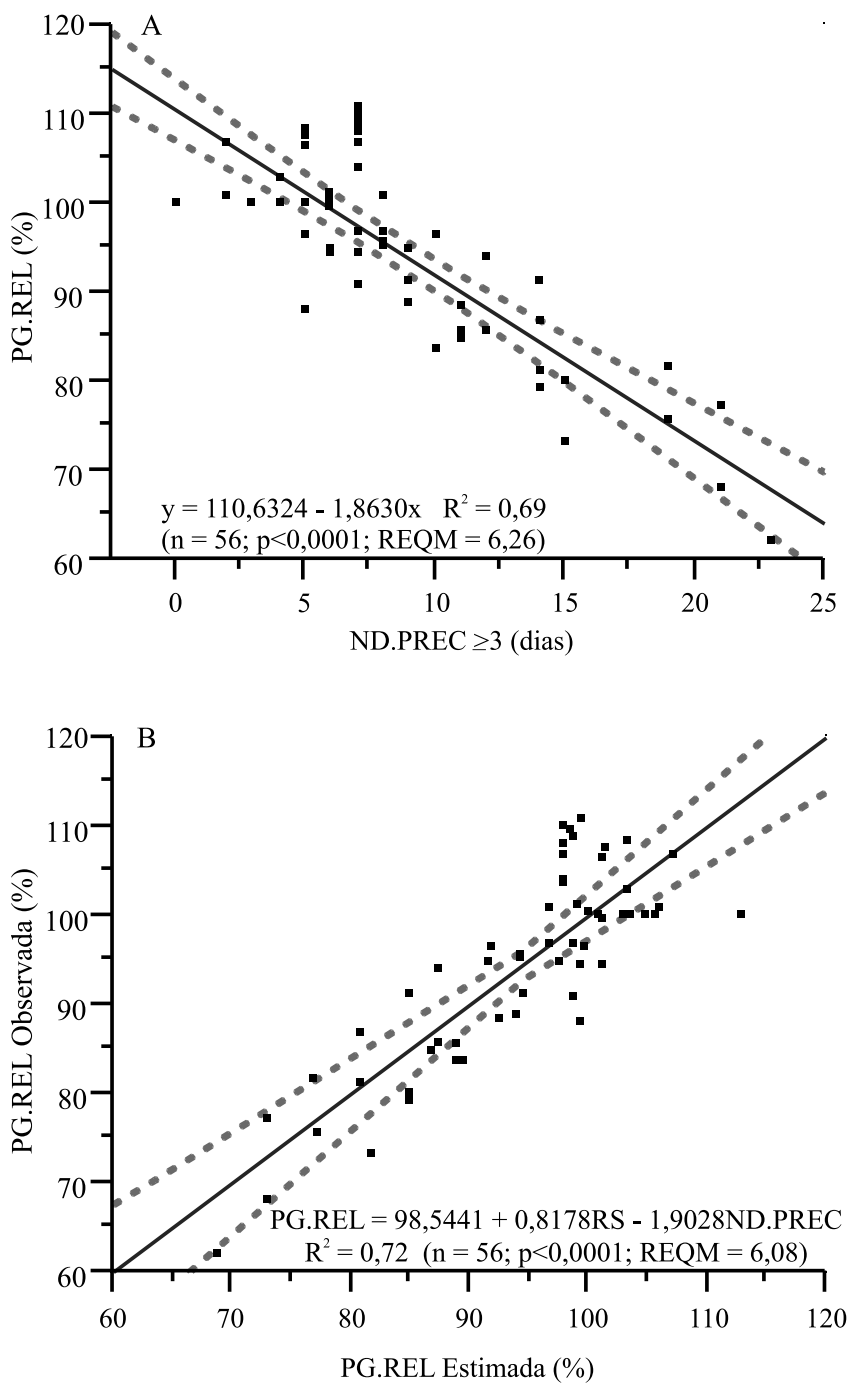

Figura 4. Estimativa das perdas relativas diárias de produtividade de soja (PG.REL), obtida a partir de regressão linear simples (A), com o número de dias com precipitação pluvial $\geq 3 \mathrm{~mm}$ (ND.PREC $\geq 3 \mathrm{~mm}$ ), ou de regressão linear múltipla (B), com as variáveis independentes número de dias com precipitação pluvial $\geq 3 \mathrm{~mm}$ e média da radiação solar global (RS, $\mathrm{MJ} \mathrm{m}^{-2}$ por dia), no período entre o estágio R8.2 e a efetiva colheita da soja. ${ }^{(-)}$Linha contínua preta, valores preditos. ${ }^{(-)}$Linha pontilhada cinza, intervalo de confiança de $95 \%$ de probabilidade. Média de sete ambientes, nas safras 2011/2012, 2012/2013 e 2013/2014, em Castro, PR e Itaberá, SP.
R8.2, estimaram-se perdas de $74,5 \mathrm{~kg} \mathrm{ha}^{-1}$. O segundo algoritmo utilizou duas variáveis, normalmente mensuradas em estações agrometeorológicas automáticas, como a média da radiação solar global (RS) e o ND.PREC $\geq 3 \mathrm{~mm}$ (Figura $4 \mathrm{~B}$ ), que resultaram em melhores estimativas da produtividade relativa de grãos (PG.REL), com valores de $\mathrm{R}^{2}=0,72$ e de $\mathrm{REQM}=6,08 \%$.

A escolha das variáveis agrometeorológicas para a composição dos dois algoritmos, representados no presente trabalho, coincide com os relatos de Queiroz et al. (1978), sobre a precipitação frequente, as baixas taxas de radiação solar global e a oscilação da amplitude térmica, nos dias que antecederam a colheita, que causaram em decréscimos quantitativos e qualitativos da soja.

Em regiões edafoclimáticas semelhantes, as informações sobre as perdas de produtividade de soja, em razão do atraso da colheita e das condições meteorológicas, podem auxiliar o agricultor a dimensionar a capacidade de suas colhedoras ou mesmo a decidir sobre a contratação de serviços terceirizados. Da mesma forma, a inserção dos algoritmos propostos em modelos regionais de previsão do tempo pode auxiliar o planejamento semanal da operação de colheita e maximizar a renda líquida de cada talhão e propriedade rural.

\section{Conclusões}

1. A umidade dos grãos de soja é influenciada diretamente pelo número de dias com precipitação pluvial igual ou superior a $3 \mathrm{~mm}$, no período entre o estádio fenológico R8.2 e a efetiva data de colheita.

2. A umidade dos grãos apresenta relação direta com a massa de mil grãos, e esta com a produtividade.

3. O estádio fenológico R8.2 apresenta as maiores produtividades de soja, independentemente das condições edafoclimáticas avaliadas e, após esse estádio, observa-se declínio desta variável, em consequência do atraso da colheita.

4. As maiores perdas de produtividade ocorrem em ambientes com alta frequência de precipitações pluviais, altas temperaturas e elevada radiação solar global; assim, dois algoritmos, com base em variáveis agrometeorológicas, são propostos, para a estimativa da perda de produtividade de soja.

Pesq. agropec. bras., Brasília, v.51, n.8, p.905-915, ago. 2016 DOI: 10.1590/S0100-204X2016000800002 


\section{Agradecimentos}

À Fundação ABC, Pesquisa e Desenvolvimento Agropecuário, pelo suporte técnico e financeiro; e à Fundação Araucária, pela concessão de bolsa.

\section{Referências}

ARAUJO, M.A.; SOUZA, J.L.M. de; TSUKAHARA, R.Y. Modelos agro-meteorológicos na estimativa da produtividade da cultura da soja na região de Ponta Grossa, Estado do Paraná. Acta Scientiarum. Agronomy, v.33, p.23-31, 2011. DOI: 10.4025/ actasciagron.v33i1.5062.

BORGES, I.O.; MACIEL, A.J.S.; MILAN, M. Programa computacional para o dimensionamento de colhedoras considerando a pontualidade na colheita de soja. Engenharia Agrícola, v.26, p.131-141, 2006. DOI: 10.1590/S0100-69162006000100015.

BRASIL. Ministério da Agricultura, Pecuária e Abastecimento. Regras para análise de sementes. Brasília, 2009. 399p.

CÂMARA, G.M. de S. Fenologia é ferramenta auxiliar de técnicas de produção. Visão Agrícola, v.5, p.63-66, 2006.

CAMOLESE, H.S.; BAIO, F.H.R.; ALVES, C.Z. Perdas quantitativas e qualitativas de colhedoras com trilha radial $\mathrm{e}$ axial em função da umidade do grão. Revista Brasileira de Engenharia de Biossistemas, v.9, p.21-29, 2015. DOI: 10.18011/ bioeng2015v9n1p21-29.

CARRARO, I.M.; BECO, A.; ROCHA, A. Efeito do retardamento da colheita sobre a qualidade de sementes de soja em Palotina, PR. Revista Brasileira de Sementes, ano7, p.123-132, 1985. DOI: 10.17801/0101-3122/rbs.v7n3p123-132.

CARVALHO, E.R.; OLIVEIRA, J.A.; CALDEIRA, C.M. Qualidade fisiológica de sementes de soja convencional e transgênica RR produzidas sob aplicação foliar de manganês. Bragantia, v.73, p.219-228, 2014. DOI: 10.1590/1678-4499.0096.

CASSIA, M.T.; VOLTARELLI, M.A.; SILVA, R.P. da; ZERBATO, C.; LIMA, P.H. de. Monitoramento da operação de colheita mecanizada de sementes de soja. Revista Brasileira de Engenharia Agrícola e Ambiental, v.19, p.1209-1214, 2015. DOI: 10.1590/1807-1929/agriambi.v19n12p1209-1214.

CASTRO, E. de M.; OLIVEIRA, J.A.; LIMA, A.E. de; SANTOS, H.O. dos; BARBOSA, J.I.L. Qualidade fisiológica de sementes de soja submetidas à chuva artificial na pré-colheita. Journal of Seed Science, v.38, p.14-21, 2016. DOI: 10.1590/2317-1545v38n1154236.

DALTRO, E.M.F.; ALBUQUERQUE, M.C. de F.; FRANÇA NETO, J. de B.; GUIMARÃES, S.C.; GAZZIERO, D.L.P.; HENNING, A.A. Aplicação de dessecantes em pré-colheita: efeito na qualidade fisiológica de sementes de soja. Revista Brasileira de Sementes, v.32, p.111-122, 2010. DOI: 10.1590/ S0101-31222010000100013.

DAVIES, R.M.; EL-OKENE, A.M. Moisture-dependent physical properties of soybeans. International Agrophysics, v.23, p.299-303, 2009.
DINIZ, F.O.; REIS, M.S.; ARAÚJO, E.F.; DIAS, L.A. dos S.; SEDIYAMA, T.; SEDIYAMA-BHERING, C.A.Z. Incidence of pathogens and field emergence of soybean seeds subjected to harvest delay. Journal of Seed Science, v.35, p.478-484, 2013a. DOI: $10.1590 /$ S2317-15372013000400009.

DINIZ, F.O.; REIS, M.S.; DIAS, L.A. dos S.; ARAÚJO, E.F.; SEDIYAMA, T.; SEDIYAMA, C.A. Physiological quality of soybean seeds of cultivars submitted to harvesting delay and its association with seedling emergence in the field. Journal of Seed Science, v.35, p.147-152, 2013b. DOI: 10.1590/ S2317-15372013000200002.

FRANÇANETO, J. de B.; KRZYZANOWSKI, F.C.; PÁDUA, G.P. de; COSTA, N.P. da; HENNING, A.A. Tecnologia da produção de sementes de soja de alta qualidade. Londrina: Embrapa Soja, 2007. 12p. (Circular técnica, 40).

GRIS, C.F.; VON PINHO, E.V. de R.; ANDRADE, T.; BALDONI, A.; CARVALHO, M.L. de M. Qualidade fisiológica e teor de lignina no tegumento de sementes de soja convencional e transgênica RR submetidas a diferentes épocas de colheita. Ciência e Agrotecnologia, v.34, p.374-381, 2010. DOI: 10.1590/ S1413-70542010000200015.

KLERING, E.V.; FONTANA, D.C.; ROGLIO V.S.; ALVES, R. de C.M.; BERLATO, M.A. Modelo agrometeorológico-espectral para estimativa da produtividade de grãos de arroz irrigado no Rio Grande do Sul. Bragantia, v.75, p.247-256, 2016. DOI: 10.1590/1678-4499.287.

LACERDA, A.L.S.; LAZARINI, E.; SÁ, M.E.; VALÉRIO FILHO, V.V. Aplicação de dessecantes na cultura de soja: teor de umidade nas sementes e biomassa nas plantas. Planta Daninha, v.21, p.427-434, 2003. DOI: 10.1590/S0100-83582003000300011.

LIMA, W.A.A. de; BORÉM, A.; DIAS, D.C.F.S.; MOREIRA, M.A.; DIAS, L.A. dos S.; PIOVESAN, N.D. Retardamento de colheita como método de diferenciação de genótipos de soja para qualidade de sementes. Revista Brasileira de Sementes, v.29, p.186-192, 2007. DOI: 10.1590/S0101-31222007000100026.

MARCANDALLI, L.H.; LAZARINI, E.; MALASPINA, I.C. Épocas de aplicação de dessecantes na cultura da soja: qualidade fisiológica de sementes. Revista Brasileira de Sementes, v.33, p.241-250, 2011. DOI: 10.1590/S0101-31222011000200006.

MARCONDES, M.C.; MIGLIORANZA, E.; FONSECA, I.C.B. de. Danos mecânicos e qualidade fisiológica de semente de soja colhida pelo sistema convencional e axial. Revista Brasileira de Sementes, v.27, p.125-129, 2005. DOI: 10.1590/ S0101-31222005000200018.

MINUZZI, A.; BRACCINI, A. de L. e; RANGEL, M.A.S.; SCAPIM, C.A.; BARBOSA, M.C.; ALBRECHT, L. P. Qualidade de sementes de quatro cultivares de soja, colhidas em dois locais no estado do Mato Grosso do Sul. Revista Brasileira de Sementes, v.32, p.176-185, 2010. DOI: 10.1590/S0101-31222010000100020.

OLIVEIRA, T.C. de; NETTO FIGUEIREDO, Z.; GRILLO NEVES, L.; FAVARE, H.G. de; PACHECO, A. P. Quantitative losses on the mechanized harvesting of soy in the region of Cáceres, Mato Grosso. Brazilian Journal of Applied Technology for Agricultural Science, v.7, p.91-96, 2014. DOI: 10.5935/PAeT. V7.N2.11. 
PÁDUA, G.P. de; FRANÇA-NETO, J. de B.; ROSSI, R.F.; CÂNDIDO, H.G. Agroclimatic zoning of the state of Minas Gerais for the production of high quality soybean seeds. Journal of Seed Science, v.36, p.413-418, 2014. DOI: $10.1590 / 2317-1545 v 36 n 41023$.

PIMENTEL-GOMES, F.; GARCIA, C.H. Estatística aplicada a experimentos agronômicos e florestais: exposição com exemplos e orientações para uso de aplicativos. Piracicaba: Fealq, 2002. 309 p.

QUEIROZ, E.F. de; NEUMAIER, N.; TORRES, E.; TERAZAWA, F.; PALHANO, J.B.; PEREIRA, L.A.G.; BIANCHETTI, A.; YAMASHITA, J. Recomendações técnicas para a colheita da soja. Londrina: EMBRAPA-CNPSO, 1978. 32p.

SCHANOSKI, R.; RIGHI, E.Z.; WERNER, V. Perdas na colheita mecanizada de soja (Glycine max) no Município de Maripá - PR.
Revista Brasileira Engenharia Agrícola e Ambiental, v.15, p.1206-1211, 2011.

SILVA-FUZZO, D.F. da; PRELA-PANTANO, A.; CAMARGO, M.B.P. de. Modelagem agrometeorológica para estimativa de produtividade de soja para o Vale do Médio Paranapanema-SP. Irriga, v.20, p.490-501, 2015. DOI: 10.15809/ irriga.2015v20n3p490.

TERASAWA, J.M.; PANOBIANCO, M.; POSSAMAI, E.; KOEHLER, H.S. Antecipação da colheita na qualidade fisiológica de sementes de soja. Bragantia, v.68, p.765-773, 2009. DOI: 10.1590/S0006-87052009000300025.

XAVIER, T. da S.; DARONCH, D.J.; PELUZIO, J.M.; AFFÉRRI, F.S.; CARVALHO, E.V. de; SANTOS, W.F. dos. Época de colheita na qualidade de sementes de genótipos de soja. Comunicata Scientiae, v.6, p.241-245, 2015.

Recebido em 15 de fevereiro de 2016 e aprovado em 24 de maio de 2016 